\title{
PENINGKATAN KOMPETENSI BAHASA JEPANG SISWA MELALUI PELATIHAN JLPT
}

\author{
Dian Bayu Firmansyah"1*, Eko Kurniawan'2, Ita Fitriana ${ }^{3}$ \\ 1,2,3Program Studi Sastra Jepang, Fakultas Ilmu Budaya, Universitas Jenderal Soedirman \\ *e-mail: dbayuf@unsoed.ac.id ${ }^{1}$ eko.kurniawan@unsoed.ac.id ${ }^{2}{ }^{\text {ita.fitriana@unsoed.ac.id }}{ }^{3}$
}

\begin{abstract}
Japanese Language Proficiency Test (JLPT) is very useful to fulfill the requirements for working or submitting a scholarships for study in Japan. JLPT exam, which is held only twice a year, requires special preparation to pass the exam. The purpose of this activity was to provide basic knowledge of the JLPT N5 exam format and to conducted special training of JLPT N5 questions drill for high school students, who have an interest in continuing their studies in Japan. A special class was held for the JLPT N5 training as an extracurricular activity, conducted by given a lecture, discussion, question and answer methods. From the survey questionnaire results conducted in the class, it is showed that the comprehension level of students towards JLPT exam type of questions is increasing. Students motivation to learn Japanese also increasing, especially in terms of developing a career path options after graduating from high school.
\end{abstract}

Keywords: JLPT N5; Japanese; high school students

\section{Abstrak}

Japanese Language Proficiency Test (JLPT) sangat berguna sebagai salah satu syarat untuk bekerja atau mengajukan beasiswa untuk studi lanjut di Jepang. Ujian JLPT yang dilaksanakan hanya dua kali dalam setahun (bulan Juli dan Desember), membutuhkan persiapan khusus agar peluang untuk lulus semakin besar. Tujuan dari kegiatan pengabdian ini yaitu untuk memberikan pengetahuan dasar mengenai format ujian JLPT N5 dan melakukan pelatihan berupa drill soal-soal JLPT N5 kepada siswa SMA, yang memiliki minat untuk lanjut studi di Jepang. Untuk mencapai tujuan tersebut, diadakan kelas khusus untuk pelatihan JLPT N5 sebagai kegiatan ekstrakurikuler dengan metode ceramah, diskusi dan tanya jawab. Hasil dari kegiatan pengabdian ini yaitu: tingkat kemampuan dan pemahaman siswa terhadap format serta soal-soal yang diujikan pada ujian JLPT semakin meningkat, terlihat dari hasil angket kuesioner yang dibagikan. Motivasi belajar siswa terhadap bahasa Jepang pun semakin meningkat, karena pilihan jenjang karir lain setelah lulus SMA menjadi terbuka lebar.

Kata kunci: JLPT N5; bahasa Jepang; siswa SMA

\section{PENDAHULUAN}

Ada empat buah keterampilan berbahasa yang mutlak wajib dikuasai oleh pembelajar bahasa asing, yaitu kemampuan membaca, menulis, menyimak dan berbicara (Primawidha et al., 2015). Keempat keterampilan tersebut pada dasarnya merupakan satu kesatuan dan bersifat catur tunggal, sehingga satu keterampilan sangat erat kaitannya dengan keterampilan yang lainnya (Haryenti, 2018).

Di dalam pengajaran bahasa Jepang, tingkat kompetensi pembelajar bahasa Jepang, dapat diukur melalui ujian Japanese Language Proficiency Test (JLPT) yang diadakan secara serentak pada bulan Juli dan Desember di seluruh dunia 
(Japan Foundation, 2017; Eva et al., 2018; Firmansyah \& Rahmawati, 2018).Ada 4 (empat) sub pokok keterampilan berbahasa Jepang yang diukur pada ujian ini, yaitu Moji-Goi (huruf-kosakata), Bunpou (tatabahasa), Dokkai (pemahaman bacaan), dan Chokai (menyimak). Keempat keterampilan berbahasa tersebut merupakan pondasi dasar agar mampu berbahasa Jepang dengan baik dan benar (Himeno, 1998; Nakashimi \& Naoko, 1991, Cahyono \& Syartanti, 2017).

JLPT merupakan ujian kemampuan berbahasa Jepang yang ditujukan bagi pembelajar bahasa Jepang yang tidak memiliki latar belakang bahasa Jepang sebagai bahasa Ibu. Ujian JLPT merupakan salah satu syarat yang dipenuhi oleh siswa yang memiliki minat dengan bahasa Jepang dan ingin berkarir dengan bidang pekerjaan yang berhubungan dengan bahasa Jepang di masa depan. Hal ini karena banyak perusahaan Jepang yang menjadikan sertifikat JLPT sebagai tolok ukur kemampuan bahasa Jepang dari pelamar yang melamar ke perusahaan tersebut (Cahyono \& Syartanti, 2017; Firmansyah \& Rahmawati, 2018; Primawidha et al., 2015).

Melalui kegiatan pengabdian yang berupa pelatihan Siswa SMA Negeri 2 Purwokerto untuk Mengikuti Japanese Language Proficiency Test level N5 ini, tim pelaksana pengabdian merancang kegiatan sedemikian rupa, dengan tujuan utama yaitu untuk meningkatkan 4 (empat) keterampilan dasar berbahasa Jepang yang diujikan pada ujian JLPT, dengan harapan dapat membantu untuk memperbesar peluang siswa agar dapat lulus pada ujian JLPT level N5. Hal ini sangat perlu dilakukan karena pada dasarnya keterampilan berbahasa hanya dapat diperoleh dan dikuasai dari banyaknya latihan dan juga praktek (Haryenti, 2018), terutama dalam melatih keterampilan untuk menjawab soal-soal JLPT.

Pelatihan JLPT dilakukan melalui penjelasan materi-materi seputar ujian JLPT, seperti latihan soal, sosialisasi model soal yang sering muncul pada ujian JLPT beserta trik untuk menjawabnya, dan terakhir diadakan ujian simulasi JLPT. Keterampilan berbahasa pertama yang diujikan yaitu yaitu Moji-Goi (hurufkosakata) yaitu pendalaman serta pemahaman materi-materi soal seputar huruf Jepang yaitu Hiragana, Katakana, dan Kanji. Pendalaman Moji perlu dilakukan karena salah satu karakteristik bahasa Jepang yang berbeda dengan bahasa Indonesia yaitu terdapat pada jenis huruf yang digunakan. Pada materi huruf Kanji JLPT N5 diharapkan siswa mampu menghafal sebanyak 105 kanji bahasa Jepang, baik dari cara baca maupun arti dan penggunaannya. Selanjutnya, pada materi Goi (kosakata), yaitu ada sekitar 800 buah kosakata bahasa Jepang yang wajib diketahui dan dikuasai oleh pembelajar bahasa Jepang. Materi keterampilan berbahasa kedua yang diujikan yaitu, Bunpou (tatabahasa), untuk mengukur kemampuan siswa dalam penggunaan tata bahasa tingkat sederhana. Materi selanjutnya yaitu, Dokkai (pemahaman bacaan), untuk mengukur kemampuan siswa dalam memahami isi bacaan bahasa Jepang sederhana. Dan materi terakhir yang diujikan yaitu Chokai (mendengarkan) yaitu siswa mampu menyimak dan memahami isi dialog sederhana bahasa Jepang yang diputar melalui media audio (Cahyono \& Syartanti, 2017; Eva et al., 2018; Firmansyah \& Rahmawati, 2018; Primawidha et al., 2015).

Kemampuan berbahasa Jepang siswa yang kurang maksimal tentu akan menjadi salah satu kendala dalam proses kelulusan pada ujian JLPT level N5. Di sisi lain, jika siswa tidak terbiasa mengerjakan soal-soal ujian JLPT yang 
menggunakan tulisan bahasa Jepang, maka akan berakibat pada tingkat penyelesaian soal-soal JLPT N5. Hal ini disebabkan karena siswa kurang latihan dan kurang familiar dengan model soal JLPT N5, sehingga dalam proses pengerjaannya tidak dapat menyelesaikan keseluruhan soal sesuai dengan alokasi waktu yang disediakan. Terbatasnya waktu latihan juga berimbas pada terbatasnya kosakata dan tata bahasa yang dimiliki oleh siswa, dan akan semakin menyulitkan siswa untuk dapat lulus dalam ujian JLPT N5. Sehingga perlu beberapa strategi khusus bagi pembelajar bahasa Jepang dalam menghadapi ujian JLPT, agar dapat meningkatkan peluang untuk lulus dalam ujian JLPT (Bachri et al., 2017; Cahyono \& Syartanti, 2017).

Tujuan dari kegiatan pengabdian kepada masyarakat ini adalah memberikan pelatihan intensif bagi siswa SMA Negeri 2 Purwokerto untuk meningkatkan kemampuan bahasa Jepang siswa, dalam mengikuti ujian JLPT N5. Kegiatan pengabdian ini akan memberikan kesempatan siswa untuk mengenal lebih jauh mengenai materi serta tipe-tipe soal JLPT N5, trik untuk menjawab soalsoal JLPT N5, dan juga memberikan pengetahuan umum mengenai belajar bahasa dan budaya Jepang, untuk meningkatkan minat siswa terhadap bahasa dan budaya Jepang. Pengenalan bahasa dan budaya Jepang, diberikan sebagai salah satu materi pengabdian dengan tujuan untuk menarik minat dan meningkatkan motivasi siswa untuk mempelajari bahasa Jepang. Karena tinggi rendahnya motivasi siswa akan berkaitan dengan tinggi rendahnya usaha atau semangat seseorang dalam melakukan sesuatu, sehingga tentu saja akan berpangur juga pada hasil yang diperoleh (Elida, 2018).

Sementara itu, manfaat yang diharapkan dari diadakannya kegiatan pengabdian kepada masyarakat ini adalah sebagai berikut.

(1) Secara efektif, kegiatan ini bermanfaat bagi siswa-siswa di SMA Negeri 2 Purwokerto, terutama dalam hal peningkatan skill berbahasa Jepang

(2) Secara praktis, kegiatan ini bermanfaat untuk membekali siswa-siswa SMA Negeri 2 Purwokerto dengan materi-materi yang berkaitan dengan bahasa Jepang khususnya dalam hal kesiapan menghadapi JLPT N5

Bagi Universitas Jenderal Soedirman, kegiatan pengabdian kepada masyarakat dengan skim penerapan IPTEK ini merupakan salah satu wujud Tridharma Universitas. Sebagai sebuah institusi, kegiatan ini akan bermanfaat karena turut andil membantu meningkatkan pengetahuan khususnya dalam bidang bahasa Jepang, mengingat tim pengabdian berasal dari jurusan Sastra Jepang, Fakultas IImu Budaya, yang mempunyai kompetensi dalam bidang bahasa Jepang.

\section{METODE}

\section{Pemecahan Masalah}

Kegiatan pengabdian masyarakat ini bertujuan untuk meningkatkan kemampuan bahasa Jepang siswa/i SMA Negeri 2 Purwokerto, terutama dalam menghadapi ujian JLPT level N5. Materi yang digunakan adalah soal-soal JLPT N5, yang sebagian besar diambil dari buku referensi asli dari Jepang yaitu "TRY! 
Nihongo Noryoku Shiken N5 - Bunpo Kara Nobasu Nihongo dan Nihongo Charenji.

\section{Khalayak Sasaran}

Khalayak sasaran dalam kegiatan pengabdian pada masyarakat ini adalah para siswa-siswa di SMA Negeri 2 Purwokerto, Banyumas. Sekolah tersebut dipilih sebagai sasaran pengabdian masyarakat ini karena memiliki kegiatan kreativitas siswa yang sangat mendukung kegiatan pengabdian masyarakat ini mengenai pembelajaran bahasa Jepang. Kegiatan tersebut dapat dilakukan dalam mata pelajaran inti pada kelas jurusan Bahasa. Berkaitan dengan hal tersebut, tim pegabdian yang berasal dari jurusan Sastra Jepang, Fakultas IImu Budaya akan memberikan pembinaan mengenai pelatihan bahasa Jepang untuk mengikuti Japanese Language Proficiency Test N5 secara intensif pada siswa-siswa di SMA Negeri 2 Purwokerto. Kegiatan tersebut diharapkan dapat memberikan dampak positif untuk meningkatkan kemampuan tingkat kompetensi bahasa Jepang siswa.

\section{Tahapan Pelaksanaan Kegiatan}

Tahapan pelaksanaan kegiatan pengabdian ini adalah sebagai berikut.

1. Melakukan penggalian informasi mengenai kreativitas siswa dalam pembelajaran bahasa Jepang.

2. Melakukan pertemuan serta koordinasi dengan pihak yang berwenang, dalam hal ini kepala sekolah yang mempunyai kedudukan dalam pemberian izin untuk pelaksanaan kegiatan pengabdian di SMA Negeri 2 Purwokerto.

3. Melakukan pre-test bahasa Jepang, untuk mengetahui tingkat pemahaman bahasa Jepang pada siswa.

4. Melakukan pelatihan teori bahasa Jepang mengenai persiapan JLPT N5. Adapun materi dalam kegiatan ini meliputi, 1) Moji, 2) Goi, 3) Bunpo, 4) Dokkai, dan 5) Chokai.

5. Melakukan pelatihan soal-soal JLPT N5 agar siswa terbiasa mengerjakan tipe soal pada JLPT N5.

6. Melakukan post-test yang merupakan simulasi untuk kesiapan siswa dalam menghadapi JLPT N5.

7. Mensosialisasikan tentang pelaksanaan JLPT N5, hal ini diharapkan seluruh siswa dapat mengikuti JLPT N5 dan mampu lulus dengan memperoleh sertifikat JLPT N5.

8. Pada akhir pelatihan, tim pengabdian akan memberikan kuesioner kepada siswa sebagai bentuk evaluasi pertama. Evaluasi pertama ini berfungsi sebagai penilaian terhadap berjalannya pengabdian di SMA Negeri 2 tersebut. Pada tahap ini tim pengabdian akan mendapat kesempatan dalam mengetahui manfaat kegiatan pengabdian yang dilakukan di SMA Negeri 2 ini.

9. Tahap akhir adalah melakukan evaluasi kedua. Pada tahap evaluasi ini, tim pengabdian akan menyiapkan alat perekam video untuk merekam berlangsungnya simulasi ujian JLPT N5 yang dilakukan oleh siswa, 
sebagai dokumentasi yang sekaligus wujud hasil dari pengabdian ini yang dapat ditampilkan dan dikenang.

Adapun nilai-nilai evaluasi yang dapat diambil selain dari kemampuan siswa dalam menyelesaikan soal-soal JLPT N5 bahasa Jepang dengan benar siswa juga dapat belajar untuk percaya diri dalam menghadapi ujian dan mengukur kemampuan diri, bertanggung jawab, bagi seluruh siswa yang mengikuti JLPT N5 di luar kota Purwokerto maupun bagi siswa yang tidak mengikuti JLPT N5 di luar kota Purwokerto.

\section{Rancangan Evaluasi}

Terdapat sebanyak tiga kali evaluasi yang akan dilaksanakan dalam kegiatan pengabdian masyarakat ini, diantaranya adalah:

1. Tes awal sebagai evaluasi awal untuk mengukur pemahaman dan pengetahuan siswa SMA Negeri 2 Purwokerto.

2. Post-test dalam kegiatan ini adalah persiapan untuk diadakannya simulasi JLPT N5. Adanya tes ini dijadikan sebagai tolok ukur efektivitas penerapan pelatihan JLPT N5. Setelah tim pengabdian menentukan soal-soal JLPT N5 yang akan diujikan, selanjutnya adalah soal-soal simulasi JLPT N5 dikerjakan siswa.

3. Salah satu tujuan akhir kegiatan ini adalah kesiapan siswa mengikuti JLPT N5. Selanjutnya evaluasi terakhir adalah evaluasi menyeluruh setelah diadakannya simulasi JLPT N5 yaitu tim pengabdian memberikan selebaran mengenai pengisian kuesioner untuk mengetahui kekurangan dan kelebihan dari kegiatan pengabdian ini. Dari hasil evaluasi, diharapkan para siswa-siswa tersebut dapat lebih meningkatkan kepercayaan diri dalam berbahasa asing dan dapat lebih meningkatkan kemampuan komunikasi bahasa Jepang mereka untuk menghadapi JLPT N5 serta kedepannya diharapkan dapat menjadi bekal siswa memiliki kemampuan berbahasa asing dengan baik dan benar terutama bahasa Jepang.

\section{Jadwal Pelaksanaan Kegiatan Pengabdian}

Berikut ini terlampir jadwal kegiatan pengabdian yang telah disusun, dalam rangka pelatihan JLPT level N5.

Tabel 1. Jadwal Kegiatan Pengabdian

\begin{tabular}{cccc}
\hline Tanggal & Waktu & Materi \\
\hline 9 Jul 2019 & $08.00 \mathrm{~s} / \mathrm{d}$ & 1.Pengenalan Program meliputi \\
& 11.00 & target, rencana dan materi.
\end{tabular}




\begin{tabular}{|c|c|c|}
\hline & & $\begin{array}{l}\text { 2.Pengenalan Pemberi materi kepada } \\
\text { peserta pelatihan. } \\
\text { 3.Pre-test }\end{array}$ \\
\hline 3 Agu 2019 & $\begin{array}{c}08.00 \mathrm{~s} / \mathrm{d} \\
11.00\end{array}$ & $\begin{array}{l}\text { 1.Pengenalan salam dalam bahasa } \\
\text { Jepang } \\
\text { 2.Pengenalan huruf Hiragana } \\
\text { 3.Pengenalan format tes JLPT }\end{array}$ \\
\hline 10 Agu 2019 & $\begin{array}{l}08.00 \mathrm{~s} / \mathrm{d} \\
11.00\end{array}$ & $\begin{array}{l}\text { 1.Pembahasan soal JLPT (Moji-Gol) } \\
\text { 2.Pembahasan soal JLPT (Bunpo) }\end{array}$ \\
\hline 24 Agu 2019 & $\begin{array}{c}08.00 \mathrm{~s} / \mathrm{d} \\
11.00\end{array}$ & $\begin{array}{l}\text { 1.Pembahasan soal JLPT (Dokkai) } \\
\text { 2.Pembahasan soal JLPT (Chokai) }\end{array}$ \\
\hline 31 Agu 2019 & $\begin{array}{l}08.00 \mathrm{~s} / \mathrm{d} \\
11.00\end{array}$ & $\begin{array}{l}\text { 1.Pembahasan soal JLPT (Moji-GoI) } \\
\text { 2.Pembahasan soal JLPT (Bunpo) }\end{array}$ \\
\hline 7 Sept 2019 & $\begin{array}{c}08.00 \mathrm{~s} / \mathrm{d} \\
11.00\end{array}$ & $\begin{array}{l}\text { 1.Pembahasan soal JLPT (Dokkai) } \\
\text { 2.Pembahasan soal JLPT (Chokai) }\end{array}$ \\
\hline $\begin{array}{l}14 \text { Sept } \\
2019\end{array}$ & $\begin{array}{l}08.00 \mathrm{~s} / \mathrm{d} \\
11.00\end{array}$ & $\begin{array}{l}\text { 1.Pembahasan soal JLPT (Moji-Goi) } \\
\text { 2.Pembahasan soal JLPT (Bunpo) }\end{array}$ \\
\hline $\begin{array}{l}21 \text { Sept } \\
2019\end{array}$ & $\begin{array}{c}08.00 \mathrm{~s} / \mathrm{d} \\
11.00\end{array}$ & $\begin{array}{l}\text { 1.Pembahasan soal JLPT (Dokkai) } \\
\text { 2.Pembahasan soal JLPT (Chokai) }\end{array}$ \\
\hline $\begin{array}{l}28 \text { Sept } \\
2019\end{array}$ & $\begin{array}{l}08.00 \mathrm{~s} / \mathrm{d} \\
11.00\end{array}$ & $\begin{array}{l}\text { 1.Pembahasan soal JLPT (Moji-Goi) } \\
\text { 2.Pembahasan soal JLPT (Bunpo) }\end{array}$ \\
\hline 4 Okt 2019 & $\begin{array}{c}08.00 \mathrm{~s} / \mathrm{d} \\
11.00\end{array}$ & $\begin{array}{l}\text { 1.Pembahasan soal JLPT (Dokkai) } \\
\text { 2.Pembahasan soal JLPT (Chokai) }\end{array}$ \\
\hline 5 Okt 2019 & $\begin{array}{l}08.00 \mathrm{~s} / \mathrm{d} \\
11.00\end{array}$ & $\begin{array}{l}\text { 1.Post-test } \\
\text { 2.Sosialisasi dan praktik budaya } \\
\text { Jepang (Origami, Soran Bushi) } \\
\text { 3.Penutupan pelatihan }\end{array}$ \\
\hline
\end{tabular}

Sebagian besar kegiatan yang disusun bertujuan untuk membiasakan siswa/i agar terbiasa melihat dan mengetahui format serta tipe-tipe soal yang diujikan ada ujian JLPT level N5. Adapun matei berupa pengenalan budaya, diberikan untuk menghilangkan rasa jenuh dan meningkatkan motivasi belajar bahasa Jepang dari siswa/i SMAN 2 Purwokerto. 


\section{HASIL DAN PEMBAHASAN}

Kegiatan Pengabdian kepada Masyarakat Berbasis Penerapan IPTEKS ini dilaksanakan di SMA Negeri 2 Purwokerto yang beralamat di Jalan Gatot Subroto No. 69, kelurahan Sokanegara, kecamatan Purwokerto Timur, kabupaten Banyumas. Kegiatan pengabdian ini diikuti oleh siswa-siswa yang mempunyai ketertarikan bahasa Jepang melalui pelatihan mengikuti Japanese Language Profeciency Test N5.

Lokasi pelaksanaan kegiatan pengabdian berjarak kurang lebih $2.8 \mathrm{~km}$ dari Universitas Jenderal Soedirman Purwokerto. Berikut dilampirkan peta dan foto lokasi SMA Negeri 2 Purwokerto.

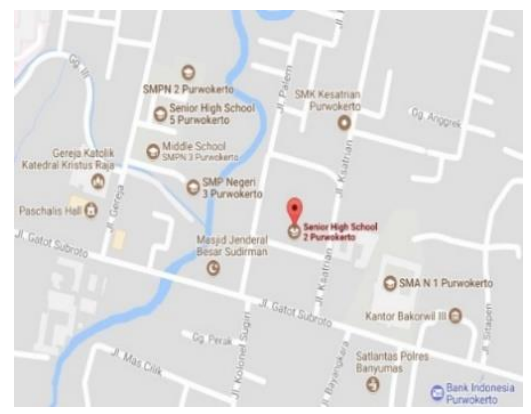

Gambar 1. Peta SMA Negeri 2 Purwokerto

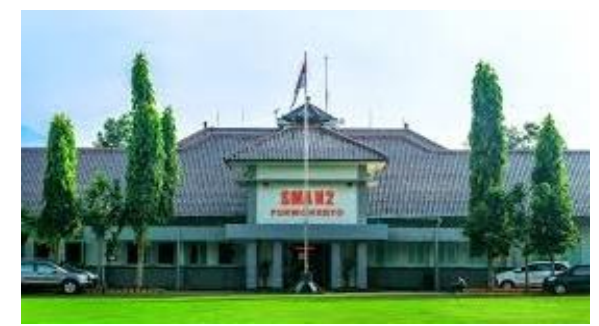

Gambar 2. SMA Negeri 2 Purwokerto

Kegiatan pengabdian masyarakat berupa pelatihan siswa SMA Negeri 2 Purwokerto untuk mengikuti Japanese language Proficiency Test N-5 dimulai dengan sosialisasi dan pengenalan, rencana dan materi program pelatihan. Peserta pelatihan merupakan siswa-siswi SMA Negeri 2 Purwokerto yang terdiri dari kelas $X$ dan XI dari berbagai peminatan baik IPA, IPS maupun bahasa yang memiliki ketertarikan untuk belajar bahasa Jepang. Sebagian besar peserta pelatihan merupakan siswa yang belum pernah belajar bahasa jepang. Sehingga materi bahasa Jepang yang diberikan pada pelatihan dimulai dari pengenalan huruf hiragana dan salam sederhana dalam bahasa Jepang. Selain belajar huruf, siswa diberi materi pelatihan berupa moji-goi (huruf dan kosakata), bunpo (tata bahasa), choukai (menyimak) dan dokkai (pemahaman bacaan). Pelatihan 
dilaksanakan secara rutin setiap hari sabtu dari pukul 08.00 sampai pukul 11.00. Pelaksanaan pelatihan berjalan secara baik dan lancar, peserta pelatihan belajar bahasa Jepang secara antusisas dan tekun. Materi pelatihan bahasa Jepang berupa huruf hiragana, kosakata dan latihan pola kalimat dapat dipahami secara baik oleh siswa-siswi SMA Negeri 2 Purwokerto. 


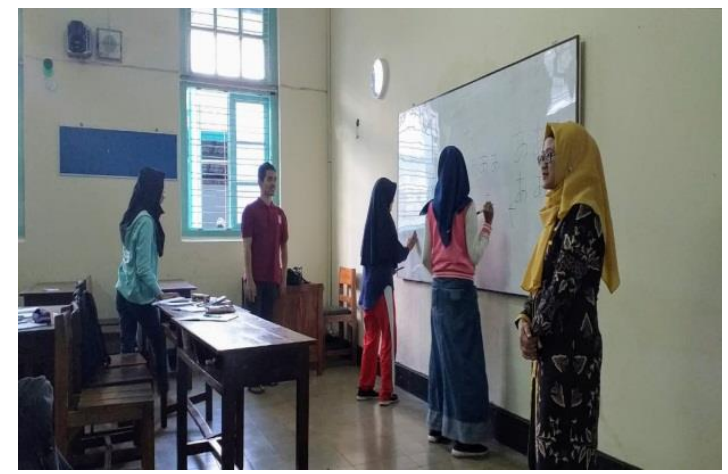

Gambar 3. Kegiatan Menulis Huruf Jepang

Pada kegiatan pengabdian ini diketahui bahwa peserta dapat mengetahui lebih banyak tentang informasi JLPT baik dari segi format soal, tata cara ujian dll. Hasil dari angket kuesioner yang diberikan terlihat bahwa terdapat peningkatan yang signifikan dari siswa/i peserta kegiatan pengabdian, terutama dalam hal pengetahuan mengenai format ujian JLPT, jenis soal-soal serta materi-materi ujian yang biasa diujikan.

Motivasi belajar bahasa Jepang siswa/i yang mengikuti kegiatan pengabdian ini dalam mempelajari bahasa Jepang pun meningkat, karena umumnya siswa/i baru mengetahui bahwa peluang untuk melanjutkan studi di Jepang sangat terbuka lebar. Pengenalan budaya Jepang yang disisipkan pada agenda kegiatan pengabdian pun menjadi dorongan lain bagi siswa/i untuk mempelajari lebih lanjut budaya Jepang di negeri asalnya.Peningkatan signifikan dari kemampuan siswa dalam menjawab soal-soal JLPT juga terlihat di akhir kegiatan pengabdian, yang tersaji dalam gambar 4 berikut ini.

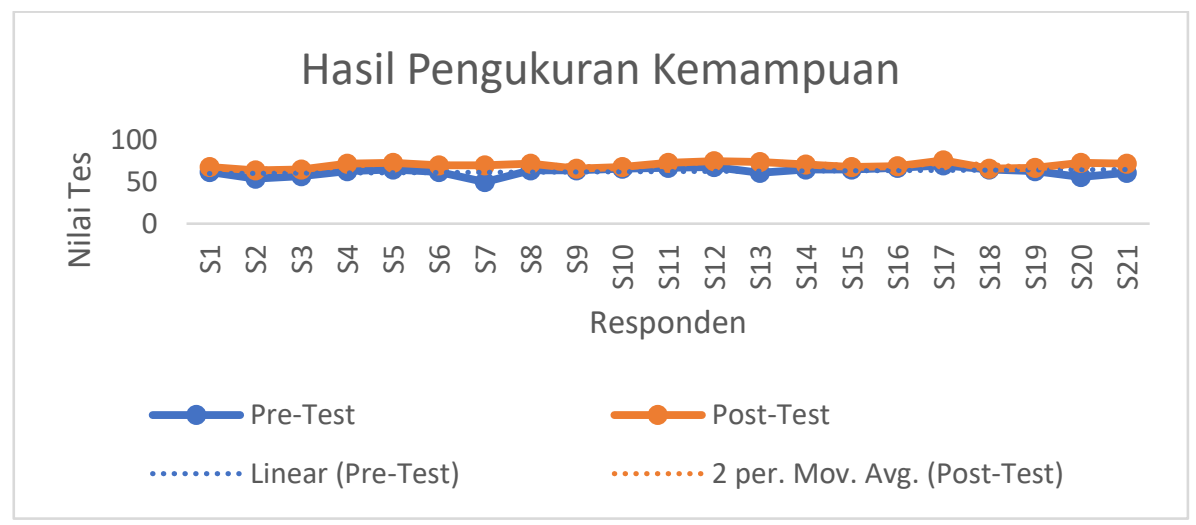

Gambar 4. Hasil Pengukuran Kemampuan Bahasa Jepang

\section{KESIMPULAN}

Salah satu indikator tercapainya pembelajaran bahasa Jepang yaitu tercapainya kelulusan ujian kemampuan bahasa Jepang (Japanese Language Proficiency Test). Ujian kemampuan bahasa Jepang memiliki lima tingkatan yaitu dimulai dari tingkatan dasar $\mathrm{N}-5$ dan tingkatan atas N1. Di era globalisasi sekarang ini, pembelajar di Indonesia perlu dibekali dengan penguasaan bahasa asing yang salah satunya adalah bahasa Jepang. Melalui pelatihan yang dilaksanakan di SMA Negeri 2 Purwokerto diharapkan dapat memberikan bekal 
penguasaan bahasa Jepang dasar bagi siswa terutama siswa yang akan melanjutkan studinya ke perguruan tinggi di luar negeri.

Pelaksanaan pelatihan Siswa SMA Negeri 2 Purwokerto untuk mengikuti ujian kemampuan bahasa Jepang (Japanese Language Proficiency Test) disambut baik oleh siswa SMA Negeri 2 Purwokerto dan berjalan dengan baik sampai pada tahap ini. Adapun beberapa kendala mengenai waktu pelaksanaan pelatihan yang sering berubah karena jadwal siswa yang padat memang sudah tidak terelakkan. Namun hal tersebut bisa diatasi dengan mengganti waktu pelaksanaan di hari lain yang kosong. Sebagai saran, pelaksanaan pelatihan perlu diperpanjang mengingat jadwal siswa yang padat serta untuk mendapat hasil yang lebih maksimal.

\section{UCAPAN TERIMA KASIH}

Tim pelaksana pengabdian mengucapkan terimakasih banyak kepada Lembaga Penelitian dan Pengabdian Kepada Masyarakat (LPPM) Universitas Jenderal Soedirman, yang telah memberikan dukungan dana terhadap kegiatan pengabdian ini, melalui skema Pengembangan IPTEKS tahun 2019.

\section{DAFTAR PUSTAKA $\leftarrow$ Arial, Bold, $11 \mathrm{pt}$}

Bachri, A. S., Firmansyah, D. B., \& Sudjianto, S. (2017). Indonesian JSL Students Beliefs and Learning Strategies in Kanji Learning. JAPANEDU: Jurnal Pendidikan Dan Pengajaran Bahasa Jepang, 2(2), 132. https://doi.org/10.17509/japanedu.v2i2.8818

Cahyono, A. B., \& Syartanti, N. I. (2017). Strategi Belajar Kelolosan Japanese Language Proficiency Test N1 (Studi Kasus Mahasiswa Sastra Jepang). Paramasastra, 4(1). https://doi.org/10.26740/parama.v4i1.1480

Elida. (2018). Peningkatan Motivasi Belajar PKN Siswa Kelas IX.7 SMP 21 Kota Pekanbaru Melalui Penerapan Model Pembelajaran Kooperatif Tipe Number Heads Together. Dinamisia: Jurnal Pengabdian Kepada Masyarakat, 2 (1), 135-143.

Eva, K., Adnyani, K., Sadyana, I. W., \& Hermawan, G. S. (2018). Persepsi Mahasiswa Terhadap Penggunaan MojiGoiGo! Sebagai Media Pembelajaran JLPT N4 Berbasis Flash. Prosiding Senari 6, 2018, pp. 364-371.

Firmansyah, D. B., \& Rahmawati, R. S. (2018). Penggunaan Media Ajar Berbasis Multimedia dalam Pembelajaran. JAPANEDU : Jurnal Pendidikan dan Pengajaran Bahasa Jepang. $3(1), 1-10$.

Haryenti. (2018). Peningkatan Kemampuan Menyimak Pidato Dengan Metode Tanya Jawab Siswa Kelas IX.2 SMP Negeri 21 Kota Pekanbaru. Dinamisia: Jurnal Pengabdian Kepada Masyarakat, 2 (1), 150-162.

Himeno, M. (1998). Koko Kara Hajimaru Nihongo Kyooiku. Japan: Hitsuji Shoboo.

Japan Foundation. (2017). Survey report on Japanese language education abroad 2015.

October 2003. https://www.jpf.go.jp/e/project/japanese/survey/result/survey15.html

Nakashimi, Y., Naoko, C. (1991). Nihongo wa Oshieru. Japan.

Primawidha, W. N., Wardhaningtyas, S., \& Nurhayati, S. (2015). Analisis Kesulitan Mahasiswa PBJ UNNES dalam Mengerjakan soal Chokai N3. Jurnal Chi'e, 4(1), 10-13. 